\title{
A case of early-onset and monophasic trigeminal autonomic cephalalgia: could it be a SUNCT?
}

\author{
Vittorio Sciruicchio $\cdot$ Michele Sardaro • \\ Delio Gagliardi · Antonio Trabacca • \\ Dante Galeone $\cdot$ Marina de Tommaso
}

Received: 3 March 2010/ Accepted: 20 April 2010/Published online: 15 May 2010

(C) Springer-Verlag 2010

\begin{abstract}
A 2-year-old female came to the Neurological Emergency Room of "Giovanni XXIII" Hospital in Bari, $6 \mathrm{~h}$ after the onset of severe facial pain, which occurred soon after awakening. Stabbing pain affected the right frontal and periorbital area, with ipsilateral conjunctival injection, swelling of the eyelids and tearing. Except the duration, from 5 to $30 \mathrm{~s}$, , the attacks were stereotyped including the occurrence and features of autonomic signs. Based on the typical clinical findings and the normal magnetic resonance imaging (MRI), we diagnosed shortlasting unilateral neuralgiform headache attacks with conjunctival injection and tearing syndrome (SUNCT). The spontaneous remission within a few hours made prophylactic therapy unnecessary. At the last follow-up, after 3 months, the patient was still symptom free. In our case, after an active period lasting 2 days the disease disappeared completely. However the typical features of the disease (unilateral pain, short duration and high frequency of the attacks, autonomic signs ipsilateral to pain, numbers of attacks) were all present. While the diagnostic criteria of the International Headache Society classification for SUNCT did not include the duration of disease, it is likely
\end{abstract}

\footnotetext{
V. Sciruicchio $(\bowtie) \cdot$ D. Gagliardi · D. Galeone Paediatric Neurology, "Giovanni XXIII"

Hospital Policlinico, Bari, Italy

e-mail: vsciru@tin.it

M. Sardaro · A. Trabacca

Scientific Institute Eugenio Medea, Association

"La Nostra Famiglia", OSTUNI (Brindisi), Brindisi, Italy

M. de Tommaso

Neurophysiopathology of Pain Unit, Neurological and Psychiatric Sciences Department, Bari "Aldo Moro" University, Bari, Italy
}

that the active period lasting 2 days could be an expression of the clinical variability of the disease.

\section{Introduction}

Short-lasting unilateral neuralgiform headache attacks with conjunctival injection and tearing, (SUNCT 3.3) is a rare idiopathic headache syndrome characterized by a strictly unilateral headache with prominent autonomic symptoms [1]. In the SUNCT the pain is abrupt in onset, of short duration, stabbing or burning in quality, and accompanied by prominent ipsilateral cranial autonomic features, particularly lacrimation and conjunctival injection. Diagnostic criteria are now established which require at least 20 attacks of unilateral, moderately severe, orbital or temporal, stabbing or throbbing pain, lasting for 5-240 s and associated with ipsilateral conjunctival injection and lacrimation [2].

The natural history of the condition is poorly understood. Generally, a clustering pattern is reported, with active phases erratically alternating with remissions. During symptomatic periods, the frequency of attacks varies

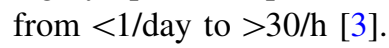

Although the international diagnostic criteria does not refer to symptomatic SUNCT, more frequently, in previous studies SUNCT-like syndrome secondary to posterior fossa abnormalities (arteriovenous malformations, brainstem lesions, skull malformation) [4-9] or associated with neoplastic lesions within the cavernous sinus and pituitary adenomas are reported [10, 11].

Many of the basic features of SUNCT, such as periodicity, autonomic symptoms and unilaterality, are shared with other syndromes, such as trigeminal autonomic cephalalgias (TACs)-i.e., cluster headache $(\mathrm{CH}, 3.1)$ and 
paroxysmal hemicrania $(\mathrm{PH}, 3.2)$ - and trigeminal neuralgia (TN, 13.1) [1].

Though similar pathophysiological basis would subtend these syndromes, the differential diagnosis is a challenge in clinical practice, in order to optimize the therapeutic approach. In addition, the very early age is a misleading factor for a correct diagnosis. While a different clinical expression of primary headaches between adult and childhood age is generally recognized, the features of TACs in children are less defined. The age of onset of SUNCT is reported from 23 to 77 years with a mean age of around 50 [3], though SUNCT-like symptoms were described in single 5- to 10-year-old cases (Table 1).

We describe a case of a 2-year-old child presenting symptoms compatible with SUNCT syndrome, aiming to add further knowledge to TACs features in childhood.

\section{Case report}

A 2-year-old female came to the Neurological Emergency Room of "Giovanni XXIII" Hospital in Bari, $6 \mathrm{~h}$ after the onset of severe facial pain, which occurred soon after awakening. During the first neurological examination, the child had a typical pain attack, consisting of an incomplete ptosis of the right eye, with impressive ipsilateral conjunctival injection and tearing. The location and intensity of pain were deduced by the fact that the child repeatedly beat her right frontal and periorbital regions, showing great suffering and crying to her mother. The attack lasted $25 \mathrm{~s}$, after which she was pale and very tired. We thus decided to admit the little patient to our Neurological Division. On the same day, the attacks were stereotyped for the occurrence and features of autonomic signs and suffering, with duration, varying from 5 to $30 \mathrm{~s}$. The child presented 40 further attacks during the afternoon, being particularly frequent after the nap and disappearing during night sleep. The next morning there were only ten attacks concentrated in the first hours after awakening. The attacks recurred in a single stab (from 1 to 6 stabs/h), for a total of more than of 40 attacks. No evident precipitating mechanisms, other than awakening, were identified. There had been no apparent complications during her mother's pregnancy and subsequent delivery and there was no first degree inheritance for primary headaches or TACs. Developmental milestones were reported to be normal. Her general physical and neurological examinations were completely normal, except during attacks. A complete ocular examination including eye movements, visual acuity and fundi were normal. The electroencephalogram (EEG) performed during the critical phase was normal. Cranium magnetic resonance imaging (MRI) and angiography MRI were completely normal without evidence of intracranial or orbital abnormalities.

Based on the typical clinical findings and the normal MRI, we excluded a secondary trigeminal autonomic syndrome, and supposed a primary SUNCT. The spontaneous remission within a few hours made prophylactic therapy unnecessary. At follow-up, after 3 months, the patient was still symptom free.

\section{Discussion}

This is the first case of SUNCT syndrome occurring in the pre-school-aged child. The repetitive paroxysmal unilateral pain attacks, associated with ipsilateral conjunctival injection, swelling of the eyelids and tearing, could satisfy the ICHD-II criteria for SUNCT. The clinical features of this rare headache resemble other exceptionally rare headaches at this age, but have the following salient differences. The prominence of autonomic signs, may contribute to exclude trigeminal neuralgia (13.1) and paroxysmal hemicrania (3.2), very rare syndromes in children. In addition, pain in SUNCT is maximal in the ophthalmic division, whereas trigeminal neuralgia most commonly affects the maxillary and/or mandibular divisions of the trigeminal nerve. The short duration of single attacks, could further exclude cluster headache (3.1). SUNCT syndrome has been reported only in four children aged from 5 to 11 [12-15]. It was reported as idiopathic in three cases and symptomatic in one case, where an astrocytoma in the ipsilateral pontocerebellar angle was described.

In our case, after an active period lasting 2 days, the disease completely disappeared. Despite the variability of
Table 1 Clinical features of pediatric SUNCT

\begin{tabular}{llll}
\hline & D'Andrea et al. [12] & Sékhara et al [13] & Unalp [14] \\
\hline Sex & Female & Male & Male \\
Age of onset (years) & 10 & 5 & 6 \\
Quality of pain & Stabbing & Burning, stabbing & Shotting \\
Severity of pain & Very severe & Very severe & Very severe \\
Site of maximal pain & Forehead & Forehead, orbit & Orbit \\
Attacks per day & 10-180/h & 4-6/h every 2-3 days & 3-4/days for 15 days \\
Total duration & Months with partial remission & 5 months & 4 years, regressed after LMT \\
\hline
\end{tabular}


primary headaches features in children, the presence of unilateral high-frequency attacks of intense and shortlasting pain, with prominent ipsilateral autonomic signs, number of attacks, seemed to completely satisfy the criteria for SUNCT diagnosis. The short duration of the syndrome occurrence, did not exclude SUNCT in our child and could be the expression of the clinical variability of this disease whose natural history is poorly understood above all in childhood. A prolonged follow-up will clarify its outcome in our young patient, contributing to add further knowledge to the natural history of this very rare disease.

Conflict of interest None.

\section{References}

1. (2004) The international classification of headache disorders, 2nd edn. Cephalalgia (Suppl. 1):46-47

2. Sjaastad O, Saunte C, Salvesen R, Fredriksen TA, Seim A et al (1989) Shortlasting unilateral neuralgiform headache attacks with conjunctival injection, tearing, sweating, and rhinorrhea. Cephalalgia 9:147-156

3. Pareja JA, Sjaastad O (1997) SUNCT syndrome. A clinical review. Headache 37:195-202

4. Bussone G, Leone M, Dalla Volta G, Strada L, Gasparotti R, Di Monda V (1991) Short-lasting unilateral neuralgiform headache attacks with tearing and conjunctival injection: the first 'symptomatic' case? Cephalalgia 11:123-127
5. Morales F, Mostacero E, Marta J, Sanchez S (1994) Vascular malformation of the cerebellopontine angle associated with 'SUNCT' syndrome. Cephalalgia 14:301-302

6. De Benedittis G (1996) SUNCT syndrome associated with cavernous angioma of the brain stem. Cephalalgia 16:503-506

7. Penart A, Firth M, Bowen JRC (2001) Short-lasting unilateral neuralgiform headache with conjunctival injection and tearing (SUNCT) following presumed dorsolateral brainstem infarction. Cephalalgia 21:236-239

8. ter Bergh JWM, Goadsby PJ (2001) Significance of atypical presentation of symptomatic SUNCT. a case report. J Neurol Neurosurg Psychiatry 70:244-246

9. Morís G, Ribacoba R, Solar DN, Vidal JA (2001) SUNCT syndrome and seborrheic dermatitis associated with craniosynostosis. Cephalalgia 21:157-159

10. Adamo MA, Drazin D, Popp AJ (2008) Short-lasting, unilateral neuralgiform headache attacks with conjunctival injection and tearing syndrome treated successfully with transsphenoidal resection of a growth hormone-secreting pituitary adenoma. J Neurosurg 109(1):123-125

11. Kaphan E, Eusebio A, Donnet A, Witjas T, Ali Chérif A (2003) Shortlasting, unilateral, neuralgiform headache attacks with conjunctival injection and tearing (SUNCT syndrome) and tumour of the cavernous sinus. Cephalalgia 23(5):395-397

12. D'Andrea GD, Granella F (2001) SUNCT-syndrome: the first case in childhood. Cephalalgia 21:701-702

13. Sékhara T, Pelc K, Mewasingh L, Boucquey D, Dan B (2005) Pediatric SUNCT syndrome. Pediatr Neurol 33:206-207

14. Unalp A, Ozturk AA (2008) SUNCT syndrome in a child: a rare cause of paroxysmal headache. Ann Saudi Med 28:386-387

15. Blättler T, Capone Mori A, Boltshauser E, Bassetti C (2003) Symptomatic SUNCT in an eleven-year-old girl. Neurology 60:2012-2013 